\title{
Study on Stress Effect of Shear Properties of Joint Surface with Saw Tooth
}

\author{
Zhanyou Luo $^{\text {1, 2, 3, a, *, Zhiqiang Xiong }}{ }^{\text {1, b }}$, Baoping Zou ${ }^{\text {1, c }}$, Man Huang ${ }^{\text {2, d, Yanli Tao }}$ 1, e \\ ${ }^{1}$ School of Civil engineering and Architecture, Zhejiang University of Science and Technology, \\ Hangzhou, Zhejiang 312000, China \\ ${ }^{2}$ Department of Civil Engineering, Shaoxing University, Shaoxing, Zhejiang 312000, China \\ ${ }^{3}$ Coastal and City Geotechnical Engineering Institute, Zhejiang University, Hangzhou, Zhejiang \\ 310058, China \\ alzy0395@163.com, ${ }^{b} 925325778 @ q q . c o m,{ }^{c}$ zoubp@zust.edu.cn, ${ }^{d}$ \\ hmcadx@126.com, etmgctyl@163.com
}

Keywords: Joint surface, Shear strength, Peak friction angle, the number of saw tooth, Saw toothed height

Abstract: A review of literature on surface morphology of rock joints indicated that the surface morphology of rock joints is a crucial factor for evaluating the stability of rock mass engineering, which have not quite got the particular attention of research scholars yet. Hence, this paper aims to study the shear characteristics of the saw tooth. Firstly, we can procure the material that has similar physio-mechanical properties as rock through testing the ratios of different raw materials, such as gypsum, gypsum retarder, and water. Then, according to the plan of design, 3 different numbers of joint specimens of saw teeth i-e (flat, ten teeth, and twenty teeth) were casted using designed molds. Finally, applying developed shear test apparatus to conduct laboratory shear tests. And for the purports of study the stress effect of rock joints, the normal stress be set 6 levels, such as $10 \mathrm{kPa}, 25 \mathrm{kPa}, 50 \mathrm{kPa}, 70 \mathrm{kPa}, 80 \mathrm{kPa}$, $100 \mathrm{kPa}$. The results showed that there are stress effects on peak shear strength, peak friction angle and peak shear displacement of saw tooth joint surface. And when there is the same length and filled saw tooth on joint surface, $\left(\tau_{\mathrm{p}-} \tau_{\mathrm{r}}\right)$ of the more the number of saw teeth is less than less number of saw teeth, and $\left(\tau_{\mathrm{p}} \tau_{\mathrm{r}}\right)$ of the flat jointed surface is less than the saw toothed joint surface.

\section{Introduction}

Joint surface is the most important part of the rock mass engineering. Most of deformation and damage of rock mass mainly occur along with the weak rock joints, so the rock mass is destroyed by the failure of the rock joint surfaces. Causing natural disasters and engineering accidents i-e (collapse, landslide and tunnel engineering) that have caused huge loss of life and property. So how to reduce or 
predict the failure of joint surfaces has been an important problem in the field of geotechnical engineering.

The study on shear strength parameter of rock joints is crucial for evaluating the stability of engineering rock mass. Domestic and foreign scholars have done a lot of research on stress effect (shear strength of rock joints presents a nonlinear variation with the increase of normal stress) of rock joint surfaces Patton [1] confirmed that the shear strength parameters of saw toothed rock joints changed law with normal stress in indoor direct shear test, and proposed the bilinear dilatancy equations. However, the stress range set can not provide the relationship between the shear strength and normal stress. And in realistic rock mass engineering, when shear failure of rock joints occurs, the shear strength of rock joints presents a nonlinear variation with the increase in normal stress. As Barton et al. [2-3] proposed JRC-JCS criterion (JRC is the roughness coefficient), in which the peak friction angle of rock joints decreases with the increase of normal stress; Bandis [4] used rock joints made with similar material to conduct indoor direct shear test and observed that shear strength of rock joint has the effect of stress and size. The stress effect on shear strength of rock joints was raised early, because selection of stress series was limited, the law of shear strength changing with normal stress is not still presented fully and the specific change law not be study yet. Recently researchers focused on the peak friction angle of rock joints under different normal stress: Peak friction angle of flat rock joints is basically a fixed value. However, in rough rock joint, the roughness of surface is the main influencing factor for the shear strength parameter of rock joint [5-6]; Grasselli et at. [7] proposed a failure criterion for shear strength of rock joints, and studied the relationship between peak friction angle of rock joint and the roughness of rock joint, normal stress and strength of rock wall. They concluded that peak friction angle decreased with the increasing of 0normal stress. Similar results were also reported by Luo et al. [8]. However, Luo et al. [2010, 2014] only studied the raw rock joints, and shear properties of other rock joint types still needed to be further explored. The stress effects not only exist in the shear strength of rock joints, but also can be found in another shear strength parameter, i-e (shear strength, peak friction and peak shear displacement). That's why the stress effect of rock joints still needs to be researched deeply.

In order to reveal the stress effect law of shear strength parameter rock joints, we selected plaster, water and retarder as the similar material of rock to simulate the performance of raw rock. 3 different kinds of surface morphologies were casted with a new mold. Several direct tests were conducted using a self-made direct shear apparatus for stress effect of rock joint under low normal stress. And 6 kinds of stress serials were selected to fully obtain the change law of stress effect of joint specimens in this research scheme. In this study, a total of 18 specimens were made to research the change law of stress effect in different number of saw tooth.

\section{Experiments}

\subsection{Required Material}

A review of literature on rock similar materials indicated that similar materials have to satisfy the following principles: (1) The similar materials should consist of loose particles; (2) The materials after molding should have a higher degree of electrical insulation, and were not affected by temperature and humidity. The mechanical properties of the similar material during process of conduct direct shear tests are relatively stable; (3) Material price is cheaper and easy to be obtained, which can reduce the cost of joint specimens production and model tests; (4) The process of specimen production should be simplified, and it can be quickly dried to speed up the cycle of model test; (5) The mechanical properties of the materials can be can extensively adjusted through changing 
materials ratio; (6) It is not toxic to the human body. In order to satisfy above principle mentioned, the joint specimens made of Gypsum were chosen to simulate physical and mechanical properties of rock joints. Because the performance of the Gypsum is similar to rock, the adjustment range of elastic modulus and compressive strength are relatively large, also the production process is simple. Meanwhile, the material source is convenient, and the gypsum plaster is widely used domestically and abroad for simulating rock properties. In order to study on shears properties of joint surfaces with saw toothed, and to match better with the self-made low-range direct shear apparatus, the ratio of gypsum and water was determined according to the uniaxial compressive tests. The material was made of low-strength gypsum, gypsum retarder and water. Samples were made using water-gypsum ratios of $0.25,0.28,0.30$, and 0.33 , the Gypsum fineness of 120 meshes, the initial setting time is 8 $16 \mathrm{~min}$, the gypsum retarder of $2 \%$ be used, maintain temperature was $35^{\circ} \mathrm{C}$, maintain time is 24 hours. The test results are shown in Table 1.The mixing ratio of plaster is tested with lime soil pressure diagram tester (figure 1).Sample size of uniaxial compressive is $70 \mathrm{~mm} \times 70 \mathrm{~mm} \times$ $70 \mathrm{~mm}$, and the using models and test specimens as shown in figure 2 . Finally, the 0.33 rate of water and gypsum was selected in this experiment.

Table 1 Uniaxial compressive strength of different ratio of water-gypsum

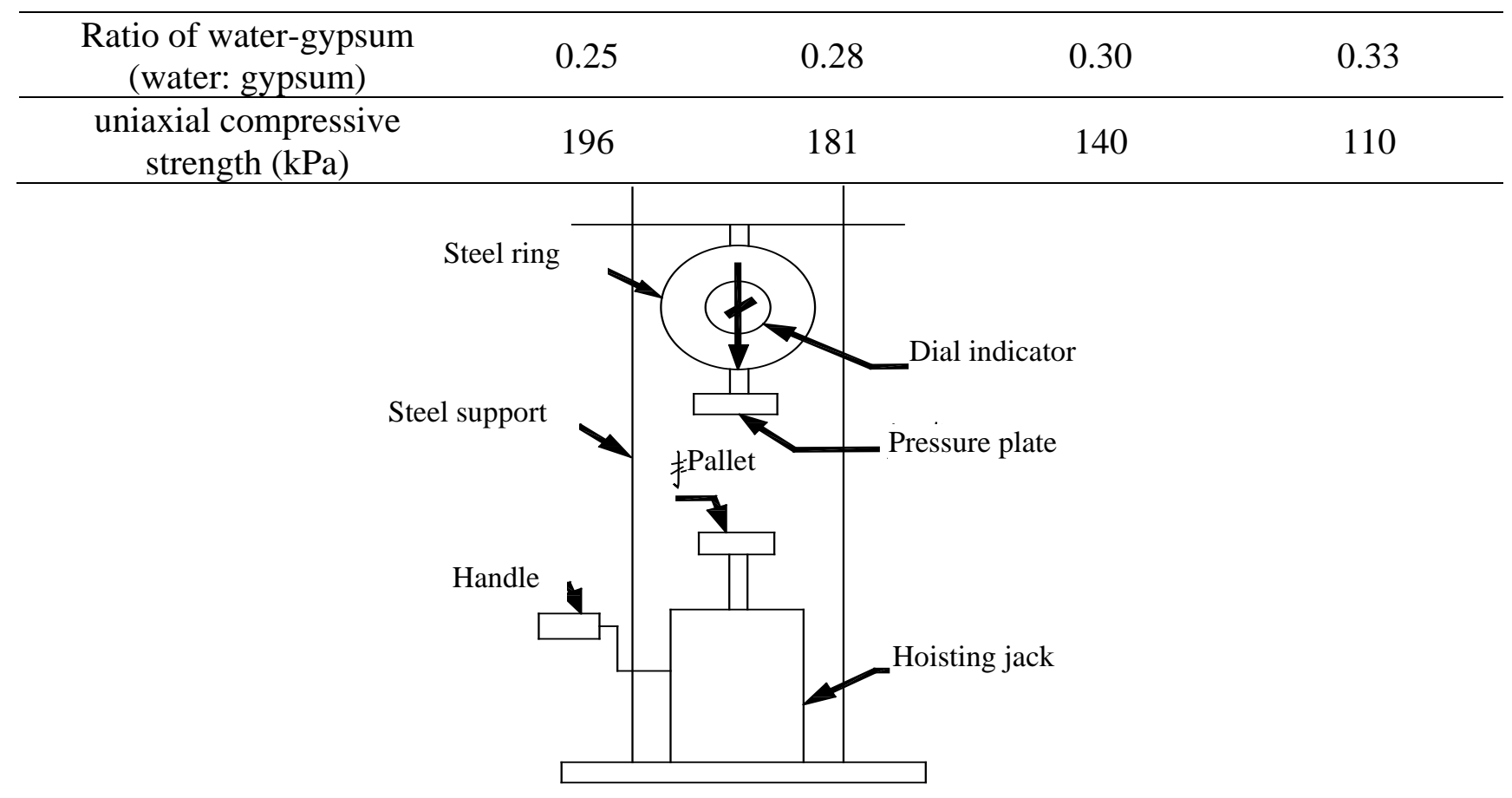

Fig. 1 Lime soil pressure diagram tester

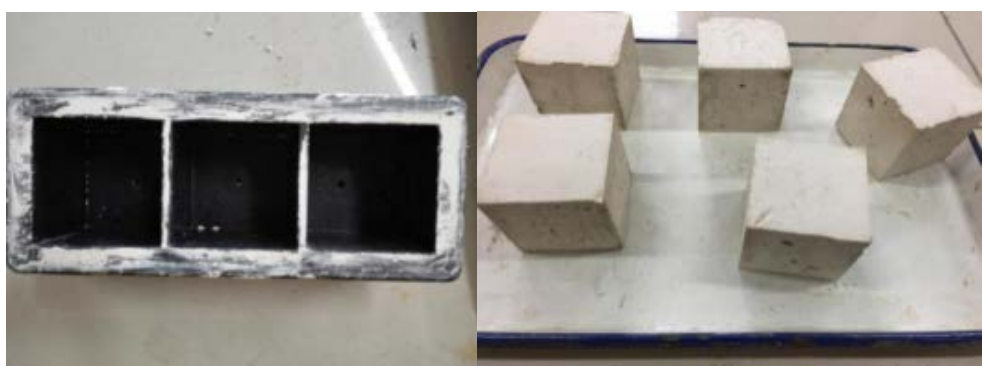

Fig. 2 Uniaxial compressive specimens and molds 


\subsection{Experiment Apparatus}

In order to conduct direct shears of low strength joint specimens, this experiment used a low-range direct shear test apparatus developed by ourselves. The rock joints direct shear apparatus consists of a platform, loading system, deformation measurement system and real time image display system, as shown in figure 3 . The maximum normal load is $10 \mathrm{kN}$, and the maximum shear load is also $10 \mathrm{kN}$. The size range of test sample is from $50 \mathrm{~mm}$ to $100 \mathrm{~mm}$. This system is equipped with a high precision load sensor, which can satisfy the accuracy requirement of shear performance test for rock joints under the action of extremely low normal load. The displacement sensor is used to measure the level deformation and normal deformation of the direct shear apparatus, the precision is $0.001 \mathrm{~mm}$ and the measurement range is from $0 \mathrm{~mm}$ to $30 \mathrm{~mm}$, the range of shear rate is from $0.02 \mathrm{~mm} / \mathrm{min}$ to $2.4 \mathrm{~mm} /$ $\min$.

The specific implementation method of the direct shear apparatus is as follows: 1) installing the samples and the sample is placed steady and accurately in the upper and lower shear box. 2) Adjusting the sensor and setting the data on the computer; 3) loading normal stress to consolidation, 4) shear tests and data collection; 5) removing out and clearing mold and equipment.

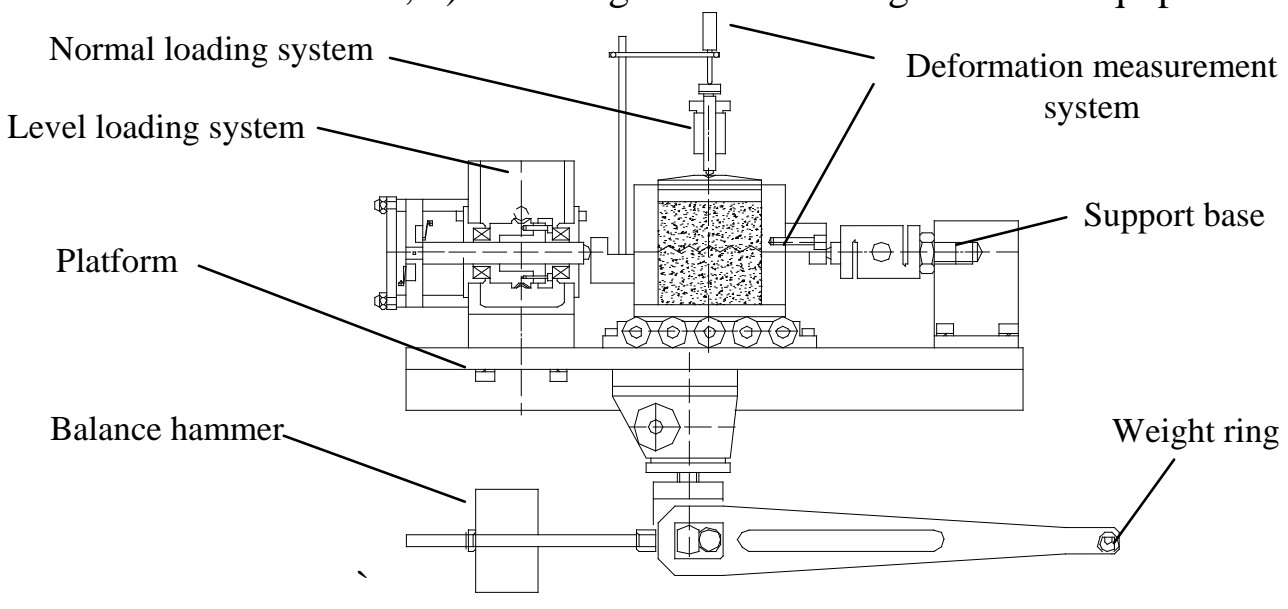

Fig. 3 ZJ-1K strain control direct shear apparatus

\subsection{Prepared Specimen and Direct Shear Test}

In order to study stress effect of joint surface of saw toothed and the effect of tooth number on stress effect, three kinds style of molds were design to obtain joint specimens of three different kinds of surface morphology in this experiment. The mold consists of side plate and bottom plate; the joint surfaces morphology was controlled with bottom plate of mold. The bottom plate saw toothed angle be designed into $0^{\circ}$ (flat) and $45^{\circ}$, meanwhile saw toothed angel of $45^{\circ}$ was designed into saw toothed height of $5 \mathrm{~mm}, 10 \mathrm{~mm}$ in bottom plate. There is 20 saw teeth in bottom pale of toothed angel of $45^{\circ}$ and saw toothed height of $5 \mathrm{~mm}, 10$ saw teeth in bottom plae of toothed angel of $45^{\circ}$ and saw toothed height of $10 \mathrm{~mm}$,the design mold as shown in figure 4 ,and specimens size are $100 \mathrm{~mm} \times 100 \mathrm{~mm} \times$ $100 \mathrm{~mm}$,as shown figure 5 .

Shear test of three kinds of saw tooth height, under different normal stress condition, was carried out to study the stress effects of the joint surfaces under different toothed height and normal stress. According to the uniaxial compressive strength of similar material, normal stress is set 6 stress levels i-e $(10 \mathrm{KPa}, 25 \mathrm{KPa}, 50 \mathrm{KPa}, 70 \mathrm{KPa}, 80 \mathrm{KPa}$ and $100 \mathrm{KPa})$. The method of displacement loading is adopted in the horizontal loading. According to review of literature and experiments, it is found that 
when the horizontal shear rate is $0.002 \mathrm{~mm} / \mathrm{s}$, the shear process of the direct shear test is relatively stable, so the horizontal shear rate of $0.002 \mathrm{~mm} / \mathrm{s}$ is used in the test process. The direct shear method is conduct through the above method mentioned.

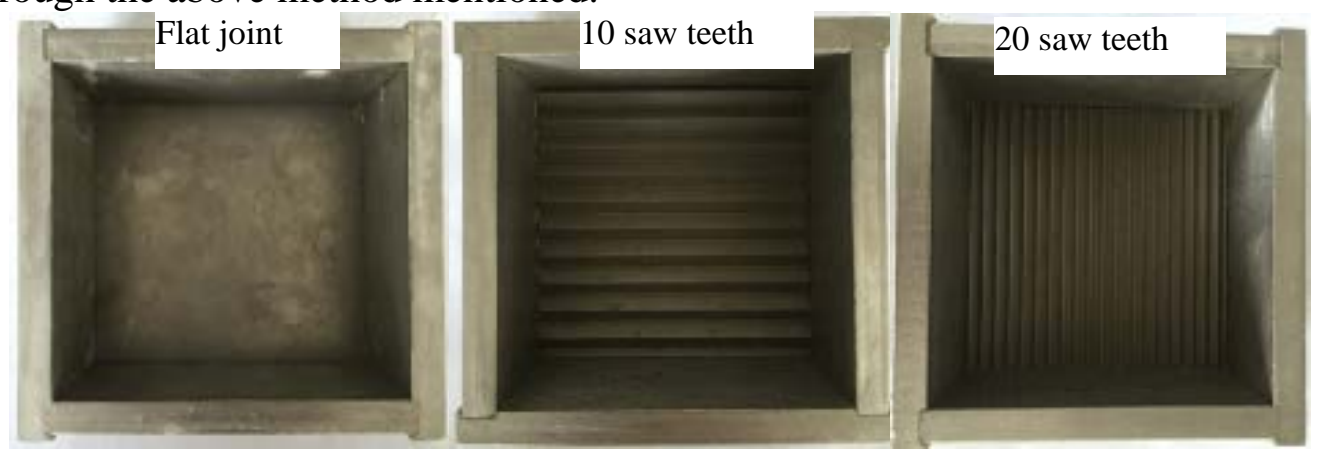

Fig. 4 Design molds

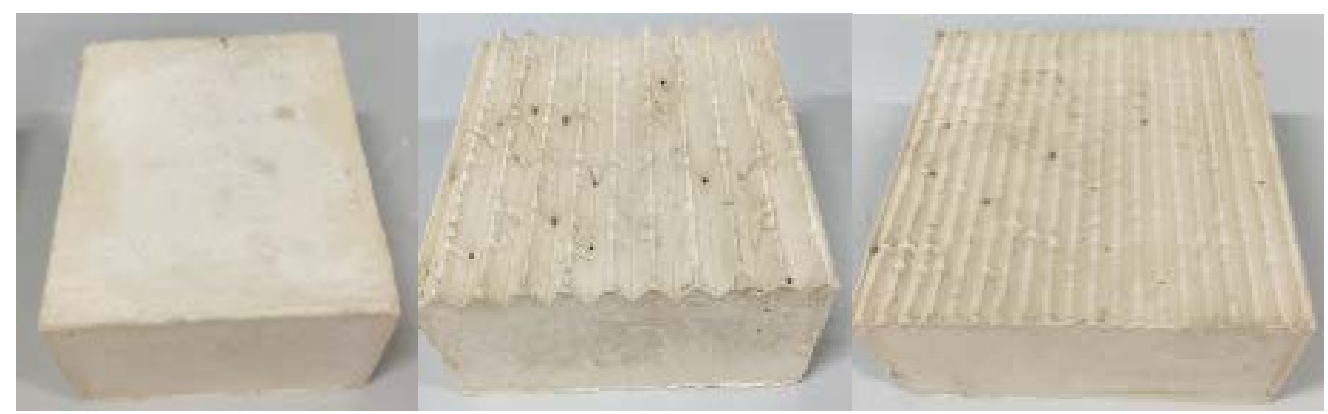

Fig. 5 Saw toothed joint specimens

\section{Test Results and Analysis}

\subsection{Test Results}

In this experiment, shear stress, shear displacement, normal stress and normal displacement can be collected. Based on the test results, the relationship between shear stress and shear displacement of each of specimens can be plotted under different the number of saw teeth, the relation figures was shown figure 123.

Form figure. 6, it can be seen that when the number of saw teeth is zero (straight joint), the shear stress first increases with increasing of shear displacement. When the peak shear strength is reached, there is not obvious variation on the shear strength with increasing of shear displacement. It can be concluded that the shear strength of the joint surfaces is mainly borne by static friction of joint surfaces before the peak shear displacement under the number of saw teeth is zero. After the peak shear displacement, the shear strength of the joint surfaces is mainly borne by the dynamic friction of joint surfaces.

Figure 7 and figure 8 show that when the number of saw teeth is 10 (saw toothed height of $10 \mathrm{~mm}$ ) and the number of saw teeth is 20 (saw toothed height of $5 \mathrm{~mm}$ ), the shear stress shows a trend of linear increasing with the increase of the shear displacement. At the same time, it can also be seen that peak shear strength of the joint surfaces increases with the increasing of normal stress. But as the normal stress increases, the amplitude of increasing in shear strength is not consistent before and after. In other word, when the normal stress is set in a larger level, the magnitude of the increase in shear strength is relatively small. So it can be concluded that this phenomenon has a relationship with the 
value of normal stress.

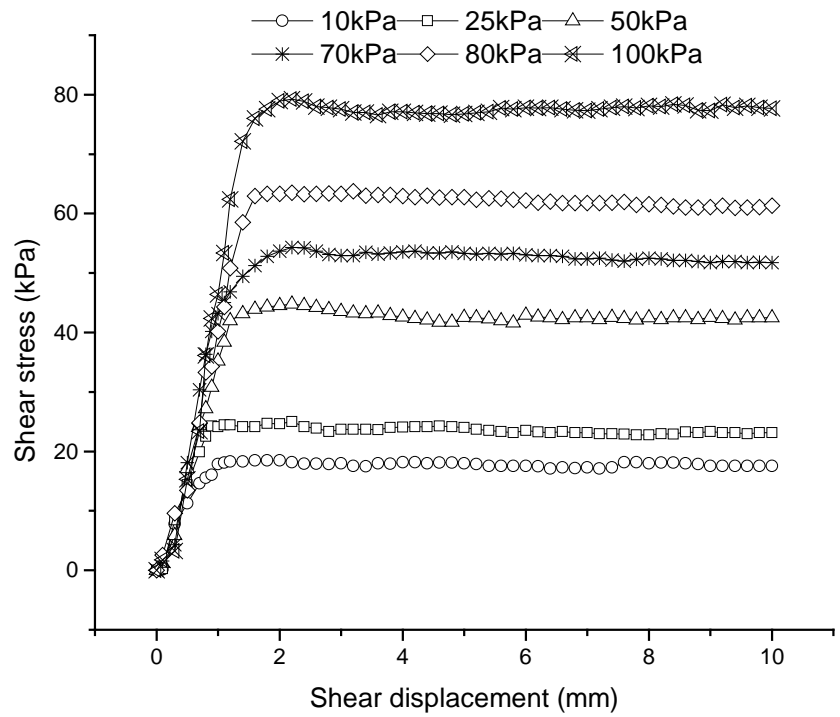

Fig. 6 Shear stress and displacement curves under different normal stresses of 0 saw tooth

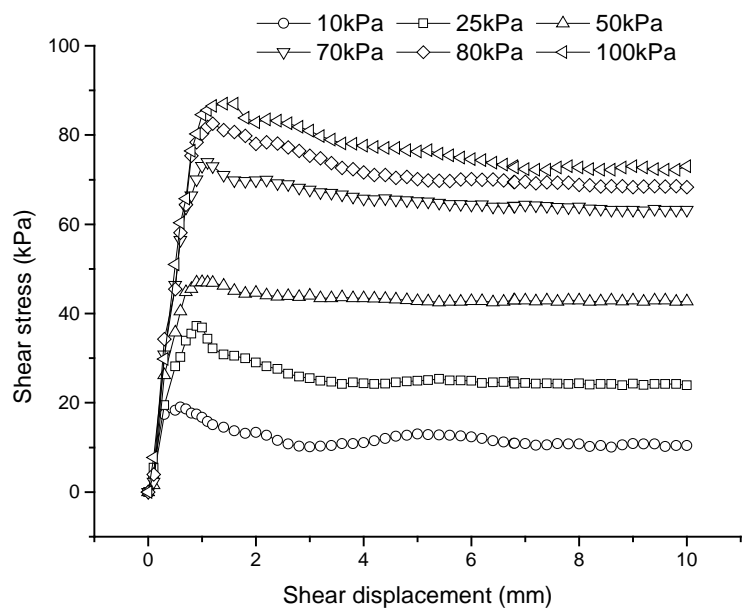

Fig. 7 Shear stress and displacement curves under different normal stresses of 10 saw teeth

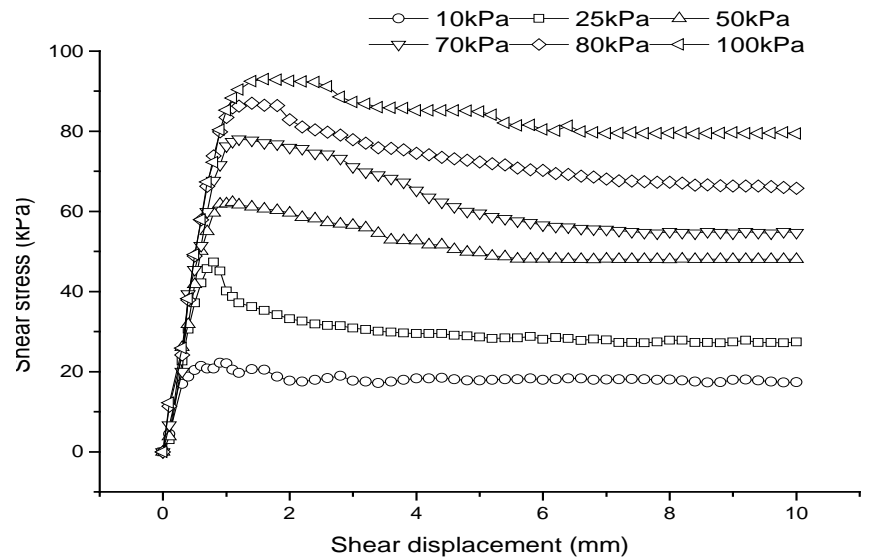

Fig. 8 Shear stress and displacement curves under different normal stresses of 20 saw teeth 


\subsection{Result Analysis}

(1) Analysis of stress effect in peak shear strength

According to value of the peak shear strength and normal stress, the relationship curve between shear strength and normal stress can be plotted, as shown in Figure 9. From the figure, it can be seen that the peak shear strength of the joint surfaces with zero number of saw teeth is linearly increase with increasing of normal stress; the peak shear strength of joint surfaces with 10 and 20saw teeth respectively linearly increases with increasing of the normal stress before the normal stress is $7 \%$ $(80 \mathrm{kPa})$ of the uniaxial compressive strength, but the increasing trend was slowed down after the uniaxial compressive strength of $7 \%(80 \mathrm{kPa})$. It can be confirmed that there is a stress effect on the peak shear strength of joint surface with 10 and 20 saw teeth. At the same time, it can be concluded that under the same length and full saw tooth in joint surface, the more the number of saw teeth or the smaller saw toothed height, and the smaller is the peak shear strength.

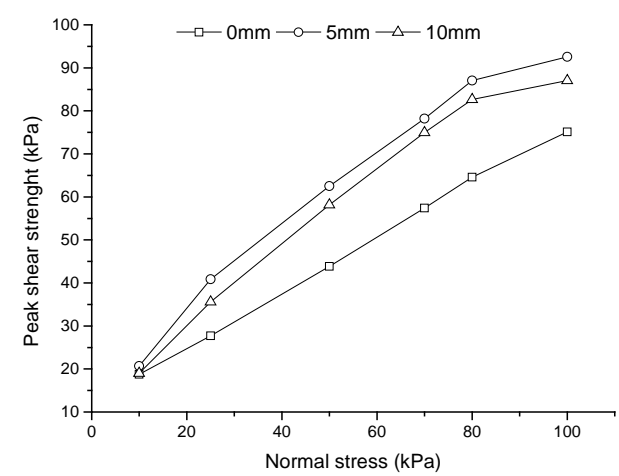

Fig. 9 Relationship curve between normal stress and shear strength under different the number of saw tooth

(2) Analysis of stress effect in peak friction angle

To study the relationship between the peak friction angle of joint surface and the normal stress, Peak friction angle of joint surface can be calculated by the anti-tangent formula of peak shear strength and normal stress, the formula is as follows:

$$
\emptyset_{\mathrm{p}}=\arctan \left(\frac{\tau_{\mathrm{p}}}{\sigma_{\mathrm{n}}}\right)
$$

Where $\tau_{\mathrm{p}}$ is the peak shear strength, $\sigma_{\mathrm{n}}$ is the corresponding normal stress.

The peak friction angle is calculated by formula (1), and the relationship curve of between the peak friction angle and the normal stress can be draw, as shown in Fig. 10. It is can be seen from the Fig. 10 that the peak friction angle is not a fixed value in the same joint surface morphology, the peak friction angle decreases with the increasing of normal stress, and the decreasing trend gradually slows down. It shows that the peak friction angles of different saw toothed heights or the number of saw teeth tend to move closer to each other. It can be confirmed that there is a stress effect on the peak friction angle; at the same time, when the normal stress is constant, the smaller the number of saw teeth or the higher the saw tooth height, the smaller is the peak friction angle. 


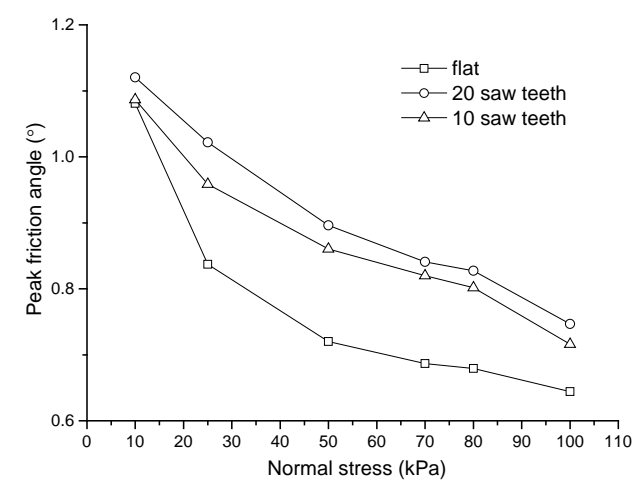

Fig. 10 The relations curve of between peak friction angle and normal stress under different the number of saw tooth

(3) Analysis of stress effect in peak shear displacement

In order to analyze the relationship between the normal shear stress and the peak shear displacement, the value of the peak shear displacement corresponding to the peak shear strength can be extracted in the above figure and relationship curve between the normal stress and the peak shear displacement can be plotted, as shown in Fig. 10. It can be seen that the peak shear displacements of both 20 and 10 saw teeth increase with the increasing of the normal stress, and it can be concluded that there is a stress effect on the peak shear displacement for the saw toothed joint surfaces. At the same time, under the same normal stress, the peak shear displacement of the rock joints with more number of saw teeth is lower than lesser, and the peak shear displacement of flat joint surface is larger than saw toothed joint surfaces. Meanwhile, the peak shear displacement of flat joints has a small increase within the stress range of normal stress less than $25 \mathrm{kPa}$, not variation within stress range of normal stress greater than $25 \mathrm{kPa}$.

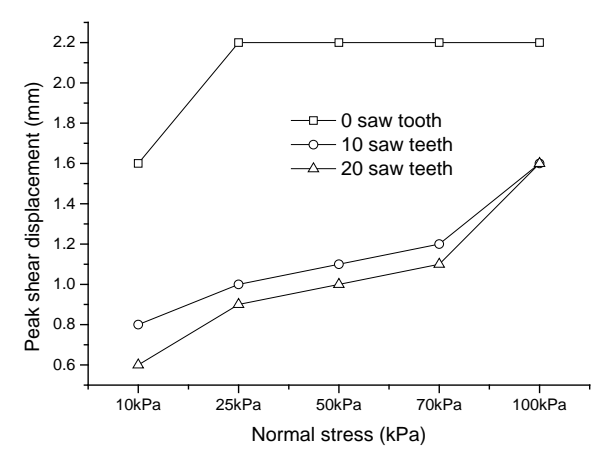

Fig. 11 The relations curve of between peak shear displacement and normal stress under different the number of saw tooth

(4) Difference analysis of peak shear strength and residual shear strength $\left(\tau_{\mathrm{p}-} \tau_{\mathrm{r}}\right)$ According to the difference value of peak shear strength and residual shear strength, the relation curve of $\left(\tau_{\mathrm{p}-} \tau_{\mathrm{r}}\right)$ and normal stress can be obtained, as shown in figure 10. It can be seen that When there is the same length and filled saw tooth on joint surface, $\left(\tau_{\mathrm{p}-} \tau_{\mathrm{r}}\right)$ of the more the number of saw teeth is less than less number of saw teeth, and $\left(\tau_{\mathrm{p}-} \tau_{\mathrm{r}}\right)$ of the flat jointed surface is less than the saw toothed joint surface. 


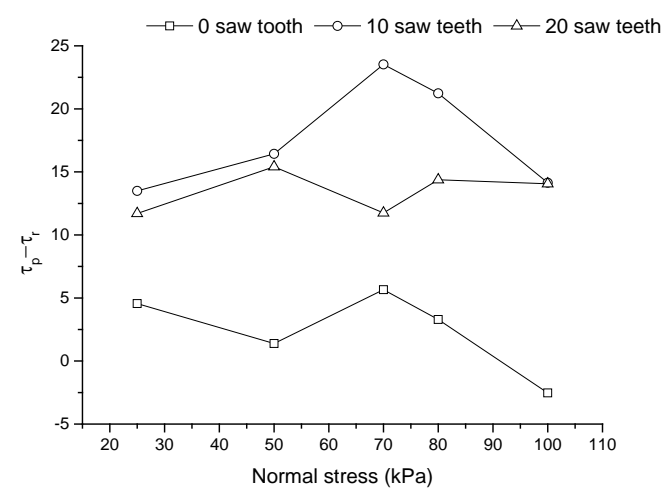

Fig. 12 The relations curve of between of $\left(\tau_{\mathrm{p}-} \tau_{\mathrm{r}}\right)$ and normal stress under different the number of saw tooth

\section{Conclusion}

18 groups of specimens were prepared by using designed molds, and laboratory tests were carried out using developed the direct shear tester of rock joint surface. The relationship between of strength parameters i-e( the peak shear strength, the peak friction angle, the peak shear displacement and $\left(\tau_{\mathrm{p}-} \tau_{\mathrm{r}}\right)$ ) and the normal stress is analyzed. The main conclusions are as follows:

1)There is a stress effect on the peak shear strength of joint surface with 10 and 20 saw teeth. While there is not stress effect on flat joint surface, and shears strength of flat joint surface linearly increase with the increasing of normal stress. When joint surface is the same length and filled saw tooth, the more the number of saw teeth, the smaller is the peak shear strength.

2) There is a stress effect on the peak friction angle. When the normal stress is constant, and the stress effect shows that peak friction angle increase with the increasing of normal stress; When joint surface is the same length and filled saw tooth, the smaller the number of saw teeth, the smaller is the peak friction angle.

3) There is a stress effect on the peak shear displacement for the saw toothed joint surfaces, and the stress effect shows peak shear displacement increases with the increasing of normal stress. However, it is not obvious for the stress effect of flat joint surface. Under the same normal stress, the peak shear displacement of the rock joints with more number of saw teeth is lower than lesser, and the peak shear displacement of flat joint surface is larger than saw toothed joint surfaces.

4) When there is the same length and filled saw tooth on joint surface, $\left(\tau_{\mathrm{p}-} \tau_{\mathrm{r}}\right)$ of the more the number of saw teeth is less than less number of saw teeth, and $\left(\tau_{\mathrm{p}-} \tau_{\mathrm{r}}\right)$ of the flat jointed surface is less than the saw toothed joint surface.

\section{Acknowledgments}

This paper was supposed by the National Natural Science Foundation of China (Grant Nos. 41572299, 41602308, 41427802, 51708507, 41172292), Zhejiang Provincial Natural Science Foundation of China(Grant Nos. LQ17E090001, LZ13D020001, LQ13D020001 and LY18D020003), "Program for 151 New Century Excellent Talents" in Zhejiang Province (12-1-076); New Century Excellent Talents in University(NCET-11-1080), Science and Technology plan Project in Zhejiang Province (Grant No.2016C33033), Zhejiang University of Science and Technology cross disciplinary research project (2015JC04Y) and The Education Project of Zhejiang Association for Science and Technology of China(Grant No.2017YCGC020). The authors thank the helps from CHAO Li in the 
process of joint specimen production and direct shear test, and the grammar guidance from Fahad Gul in this paper.

\section{References}

[1] Patton F D. Multiple Modes of Shear Failure in Rock[C]//Proceedings of the First Congress of International Society of Rock Mechanics. Lisbon, Portugal: [s. n.], 1966: 509-513.

[2] BARTON N. Review of a new shear strength criterion for rock joints[J]. Engineering Geology, 1973, 7(4):287-332.

[3] Barton N, Bandis S. Review of Predictive Capability of JRC-JCS Model in Engineering Practice[C]//Barton N, Stephansson O ed. Rotterdam: Proceedings of the International Symposium on Rock Joints, 1990, 603-610.

[4] BANDIS S, LUMSDEN A C, BARTON N. Experimental studies of scale effects on the shear behaviour of rock joints[J]. International Journal of Rock Mechanics and Mining Sciences and Geomechanics Abstracts, 1981, 18(1):1-21.

[5] FENG Q, FARDIN N, JING L, et al. (2003) A new method for in situ non-contact roughness measurement of large rock fracture surfaces[J]. Rock Mechanics and Rock Engineering, 36(1):3-25.

[6] Xia Caichu, Tang Zhicheng, Song Yinglong, et al. (2011). Analysis of relationship between joint peak shear displacement and its influence factors[J]. Rock and Soil Mechanics, 32(6): 1654-1658. (in Chinese)

[7] Grasselli G. (2006). Shear Strength of Rock Joints Based on Quantified Surface Description[J]. Rock Mechanics and Rock Engineering, 39(4): 295-314.

[8] Luo Zhanyou, Du Shigui, Huang Man. (2014)" Experimental study of stress effect on peak friction angle of rock joint. [9] Du Shigui, Huang Man, Luo Zhanyou, et al. (2010). Similar material study of mechanical prototype test of rock structural plane [J]. Chinese Journal of Rock Mechanics and Engineering,29(11):2263-2270. (in Chinese) 